\title{
Cellular and matrix interactions during the development of T lymphocytes
}

J.J.T. O wen,

D.E. McLoughlin,

R.K. Suniara and

E.J. Jenkinson
Department of Anatomy, M edical School, The University of Birmingham, Edgbaston, Birmingham, UK

\section{Correspondence \\ J.J.T. O wen \\ Department of Anatomy \\ Medical School \\ The University of Birmingham \\ Edgbaston \\ Birmingham B15 2TT \\ UK \\ Fax: + 44-(0)121-414-6815 \\ E-mail: d.jones.1@bham.ac.uk \\ Presented at the 5th Brazilian \\ Symposium on Extracellular \\ Matrix - SIMEC, Angra dos Reis, \\ RJ,Brasil, September 7-10, 1998.}

Received 0 ctober 19, 1998

Accepted November 4, 1998

\begin{abstract}
The thymus contains an extensive extracellular matrix. Although thymocytes express integrins capable of binding to matrix molecules, the functional significance of the matrix for $\mathrm{T}$ cell development is uncertain. We have shown that the matrix is associated with thymic fibroblasts which are required for the $\mathrm{CD} 44^{+} \mathrm{CD} 25^{+}$stage of double negative $\left(\mathrm{CD}^{-} 8^{-}\right)$thymocyte development. The survival of cells at this stage is dependent on IL-7 and we propose that the role of fibroblasts is to present, via the matrix, IL-7 to developing T cells.
\end{abstract}

Key words

- Extracellular matrix

- Epithelial cells

- Fibroblasts

- Integrins

- Interleukin-7

- Thymus

\section{Introduction}

The thymus is a major site of $\mathrm{T}$ cell development, although there are extrathymic pathways especially in the gastrointestinal tract. Within the thymus, $T$ cells are derived from blood-borne stem cells which migrate from sites of haemopoiesis into the thymic microenvironment. The nature of these stem cells, i.e., whether they are multipotential with respect to haemopoietic development or whether they are already restricted to the $\mathrm{T}$ cell lineage, has been debated for some time without a definitive outcome. Similarly, although the development of stem cells into Tlymphocytes is known to depend upon interactions with cells of the thymic stroma, the nature of these interactions has remained elusive (1).

In fact, the thymic stroma is complex and consists of epithelial cells derived from the pharynx as well as macrophages and dendritic cells derived from haemopoietic pre- cursors. Savino et al. (2) also pointed out that the thymus contains a prominent extracellular matrix (ECM) which is present from the earliest phases of ontogeny and these authors suggested that it played an important role in $\mathrm{T}$ cell development. The potential functional significance of the ECM is strengthened by the fact that developing $\mathrm{T}$ cells express integrins which are capable of binding to matrix molecules.

Developing T cells pass through two important checkpoints during their maturation within the thymus. The first occurs when cells are passing through the immature, double negative (DN; $\mathrm{CD}^{-} 8^{-}$) stage of development and depends on expression of the $\mathrm{T}$ cell receptor (TCR) $\beta$ chain. This checkpoint controls the maturation of DN cells to the double positive (DP; $\mathrm{CD} 4^{+} 8^{+}$) stage and is driven by the pre-TCR complex which consists of the TCR $\beta$ chain, the pre-T $\alpha$ chain and components of the $\mathrm{CD} 3$ signalling complex (3). The second checkpoint is regu- 
lated by the $\alpha \beta$ TCR complex expressed on DP cells which, following interaction with peptide/MHC complexes on thymic epithelial cells, drives their maturation into single positive (SP; $\mathrm{CD} 4^{+}$and $\mathrm{CD} 8^{+}$) $\mathrm{T}$ cells in a process known as positive selection (4). It is important to note that thymocytes removed from the thymic stroma fail to develop in vitro even in the presence of cytokines. Hence it is likely that stromal cells provide signals for most phases of thymocyte development. Moreover, the three-dimensional structure of the stroma is important because only limited $\mathrm{T}$ cell development is obtained on stromal monolayers, perhaps because stromal cells undergo a number of functional changes in monolayers (5).

In this paper, we will focus on studies in which the thymic microenvironment has been reconstructed in three dimensions using a reaggregation technique whereby purified populations of stromal cells are associated with thymocytes at defined stages of development. These studies point to the importance of a fibroblast associated ECM during the earliest $\mathrm{DN}$ phases of $\mathrm{T}$ cell development.

\section{The thymus contains an ECM associated with fibroblasts}

Immunocytochemical techniques have been used to demonstrate collagen, fibronectin and laminin within the thymus. In particular, the ECM has been associated with medullary regions of the thymus but it is also present within the cortex (6). Although thymic epithelial cells and especially thymic

CD4-8- (double negative) stages of $\alpha \beta$ T cell development

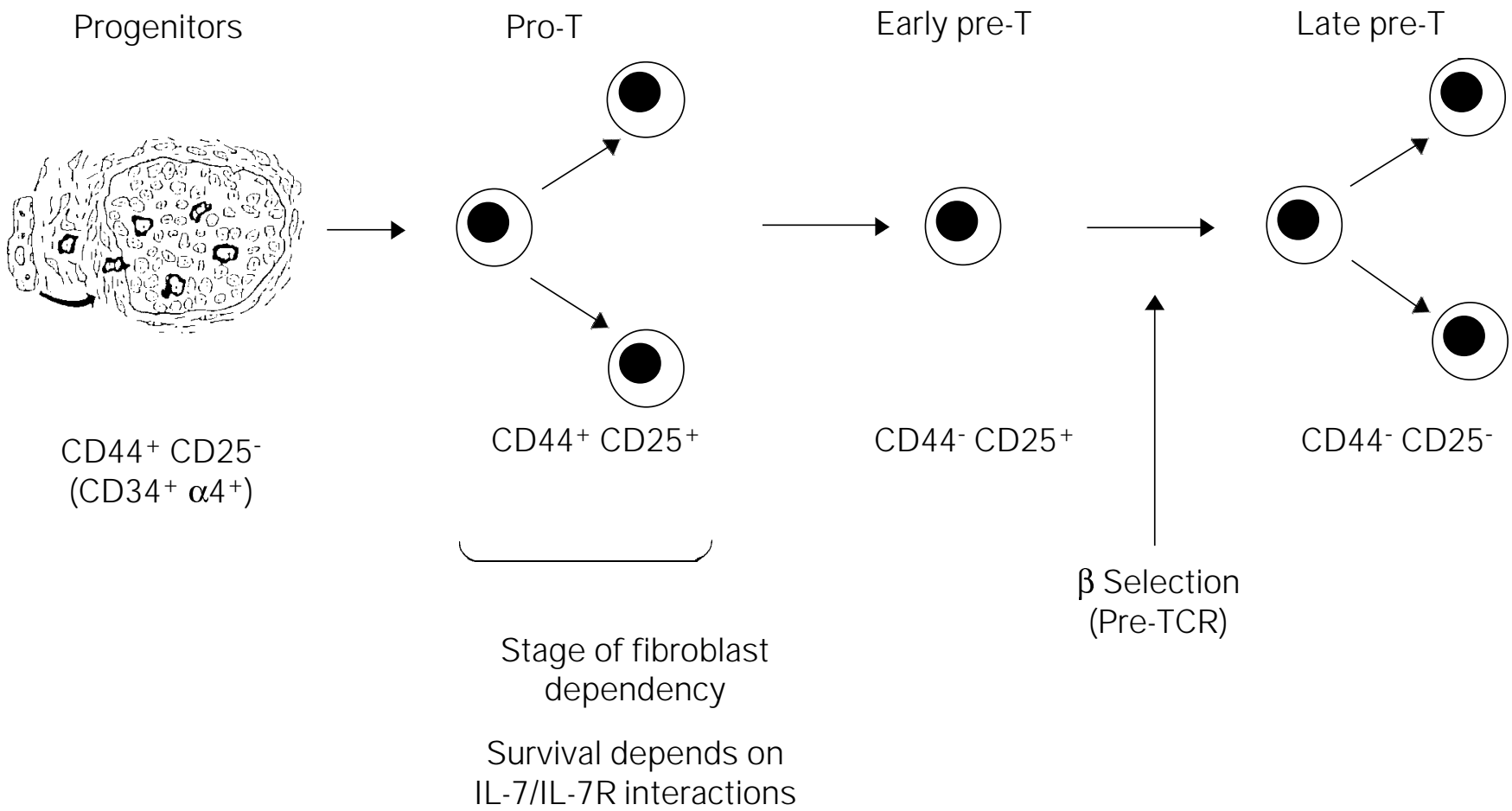

Figure 1 - Stages of double negative $\left(\mathrm{CD} 4^{-} 8^{-}\right) \alpha \beta T$ cell development. The $\mathrm{CD} 44^{+}$stage requires both fibroblast/ECM interactions with developing thymocytes as well as IL-7/IL-7R interactions. 
epithelial cell lines are known to make the constituents of the ECM, thymic fibroblasts but not thymic epithelial cells express the $\alpha 5$ $\beta 1$ integrin which is known to be involved in matrix deposition. Also, in short-term primary cultures of thymic epithelial cells and fibroblasts, we have found that an ECM is associated with fibroblasts but not with epithelial cells (7). Hence we have concluded that the thymic stroma contains a prominent fibroblast-associated ECM as well as the more widely recognised network of interconnecting epithelial cells.

\section{Fibroblasts are required for early $\mathrm{T}$ cell development}

In order to analyse the importance of the various cell types that make up the stroma, we have used a technique in which purified stromal cell populations are prepared by immunomagnetic selection from trypsinised thymic lobes. Prior to trypsinisation, embryonic thymic lobes are cultured in the presence of 2-deoxyguanosine which is toxic for lymphoid cells but not for stromal cells. Purified stromal cells are reaggregated with defined $\mathrm{T}$ cell precursors to reform lobes which can be maintained in organ culture. Using this approach, we have shown that DN thymocytes but not DP thymocytes require fibroblasts as well as epithelial cells for their development (7). The DN stage has been sub-divided into 4 distinct developmental compartments based on expression of CD44 and CD25 (Figure 1). During the first phases (thymic progenitors and pro-T cells), thymocytes express high levels of CD44 whereas in the second two phases (early and late preT cells) CD44 is down-regulated. By purifying $\mathrm{CD}_{4} 4^{+}$and $\mathrm{CD} 44^{-} \mathrm{DN}$ cells and reaggregating them with purified stromal cells, we have shown that fibroblast dependency is confined to the $\mathrm{CD} 44^{+}$stage of T cell development. Hence these studies suggest that a fibroblast associated ECM might be most important at the $\mathrm{CD} 44^{+}$stage.

\section{Interactions between developing $T$ cells and the ECM}

As mentioned earlier, a number of studies have identified integrins on developing thymocytes with the potential of binding to ECM molecules. In particular, $\alpha 4 \beta 1, \alpha 5 \beta 1$ and $\alpha 6 \beta 1$ are known to be expressed on thymocytes and are present at highest levels during the DN phase of $\mathrm{T}$ cell development (8). Moreover, immature T cells have been shown to be capable of binding to matrix constituents indicating that their integrin receptors are active. The potential functional importance of such interactions is also strengthened by evidence that antibodies to CD44 and $\alpha 4$ interfere with the development of immature $\mathrm{CD} 44^{+}$thymocytes in reaggregate organ cultures (7). Recent molecular genetic approaches have also pointed to the importance of integrins during $\mathrm{T}$ cell development. Thus, in mutant mice lacking ß1 integrins, lymphoid stem cells are blocked in their ability to produce T lymphocytes (9) and also mice lacking $\alpha 4$ integrin have impaired $T$ cell development after birth (10). In the latter case, the defect is at the level of development of DN cells into DP cells and so again focuses on the DN stage of development as important in integrin/matrix interactions.

\section{Growth factors, the ECM and $T$ cell development}

Thymocytes express a number of cytokine receptors and respond to cytokines in vitro. However, gene knockout studies have failed to reveal essential functions for many of the cytokines with the exception of IL-7/- mice, in which there is a greatly reduced level of thymopoiesis (11). Similarly, mutant mice lacking expression of the IL-7 receptor $\alpha$ chain have defective thymocyte development (12). An initial effect due to the lack of IL-7 is a reduced number of $\mathrm{DN} \mathrm{CD} 44^{+} \mathrm{CD} 25^{+}$ cells. It is interesting that introduction of a 
transgenic bcl-2 molecule into these mice restores normal $\mathrm{T}$ cell development (13). Since bcl-2 is known to be important in enhancing cell survival, these results suggest that IL-7 might provide a survival signal for thymocytes which are at a stage of development where we have shown there is a need for fibroblasts.

In a previous study, using a semi-quantitative PCR technique, we have shown that IL-7 is a product of thymic epithelial cells but not of other thymic stromal cells (14). However, IL-7 is known to bind to sulphated glycosaminoglycans in the ECM (15). In a recent study on early pre-B cell development it was shown that direct contact between bone marrow stromal cells and pre-B cells is required for IL-7 to function (16). These authors showed that there is an impaired ability of bone marrow stromal cells to present IL-7 during B-lymphopoiesis with age. Hence, in the thymus, IL-7 might be presented to $\mathrm{CD}_{4} 4^{+} \mathrm{DN}$ cells on fibroblast associated ECM. In addition, the interaction between thymocytes and the ECM via CD44 and integrins might be important in focusing IL-7 onto $T$ cell precursors. In fact it has been suggested that IL-7 itself might further potentiate such interactions (17).

Hence in this scheme, IL-7, although produced by thymic epithelial cells, would need to be presented by the ECM during a close interaction between immature thymocytes and their integrin receptors with molecules of the ECM. IL-7 presented in this way would promote pro-T cell survival at the CD $44^{+}$stage and allow progression to later stages.

It is interesting to note that in at least two situations, i.e., in mutants lacking expression of $\alpha 4$ and mutants lacking expression of the IL-7 receptor $\alpha$ chain defects of thymopoiesis, are more evident in the postnatal thymus than during foetal life $(10,12)$. The reasons for these differences are unclear but it should be remembered that the kinetics of
T cell development are likely to be different in the foetus than in the adult. Thus, in the foetus, stem cells enter the thymus in waves with the initial wave occurring at the 12th to 13th day of gestation and hence developmental events are synchronized during foetal development with major populations of cells passing through each developmental stage. Perhaps under these circumstances it is more likely that some cells may survive the $\mathrm{CD} 44^{+}$stage, even in the absence of integrin and IL-7 interactions, than in the adult where precursor populations are likely to be more limiting.

\section{Final considerations}

We have discussed evidence that the known importance of fibroblasts in the early development of DN thymocytes might depend upon the presentation of IL-7 through matrix molecules which are associated with fibroblasts but not with thymic epithelial cells. We are carrying out experiments to test this hypothesis by associated IL-7-dependent pre-B cell lines with either purified thymic epithelial cells or with epithelial cells and fibroblasts. Given the total dependence of these lines on IL-7 presentation, it should be possible to determine the importance of fibroblasts as presenters of IL-7 in the survival and growth of these lines. It might also follow that the necessity for fibroblasts during early $\mathrm{T}$ cell development can be overcome if sufficient recombinant IL-7 is added to reaggregate cultures of purified epithelial cells and $\mathrm{CD}_{4} 4^{+}$cells. Finally, it should be noted that IL-7 is unlikely to be the only factor influencing the development of early $T$ cell precursors. Indeed it is known that the interaction between c-kit on thymocytes and stem cell factor on thymic stromal cells is also involved in early $\mathrm{T}$ cell development. Ckit and IL-7 seem to act in concert since their combined absence in mutant mice leads to a very severe defect in T cell development (18). 


\section{References}

1. Anderson G, Moore NC, Owen JJT \& J enkinson EJ (1996). Cellular interactions in thymocyte development. Annual Review of Immunology, 14: 73-99.

2. Savino W, Villa-Verde DMS \& LannesVieira J (1993). Extracellular matrix proteins in intrathymic $T$ cell migration and differentiation. Immunology Today, 14: 158-161.

3. von Boehmer $\mathrm{H} \&$ Fehling $\mathrm{HJ}$ (1997). Structure and function of the pre-T cell receptor. Annual Review of Immunology, 15: 433-452.

4. Marrack P \& Kappler J (1997). Positive selection of thymocytes bearing $\alpha ß$ T cell receptors. Current Opinion in Immunology, 9: 250-255.

5. Anderson K, Moore NC, McLoughlin DE, J enkinson EJ \& Owen J J T (1998). Studies on thymic epithelial cells in vitro. Developmental and Comparative Immunology, 22: 367-377.

6. Lannes-Vieira J , Dardenne M \& Savino W (1991). Extracellular matrix components of the mouse thymus microenvironment: ontogenetic studies and modulation by glucocorticoid hormones. J ournal of Histochemistry and Cytochemistry, 39: 15391546.

7. Anderson $\mathrm{G}$, Anderson $\mathrm{KL}$, Tchilian $\mathrm{EZ}$, Owen J J T \& J enkinson EJ (1997). Fibroblast dependency during early thymocyte development maps to the $\mathrm{CD} 25^{+} \mathrm{CD} 44^{+}$ stage and involves interactions with fibro- blast matrix molecules. European J ournal of Immunology, 27: 1200-1206.

8. Utsumi K, Sawada M, Narumiya S, Nagamine J , Sakata T, Iwagami S, Kita Y, Teraoka H, Hirano H, Ogata M, Hamaoka T\& Fujiwara H (1991). Adhesion of immature thymocytes to thymic stromal cells through fibronectin molecules and its significance for the induction of thymocyte differentiation. Proceedings of the National Academy of Sciences, USA, 88: 5685-5689.

9. Hirsch E, Iglesias A, Potocnik AJ, Hartmann U \& Fassler R (1996). Impaired migration but not differentiation of haematopoietic stem cells in the absence of $ß 1$ integrins. Nature, 380: 171-175.

10. Arroyo AG, Yang J T, Rayburn $H$ \& Hynes RO (1996). Differential requirements for $\alpha 4$ integrins during fetal and adult hematopoiesis. Cell, 85: 997-1008.

11. Moore TA, von Freeden-J effry $U$, Murray R \& Zlotnik A (1996). Inhibitor of $\gamma \delta$ T cell development and early thymocyte maturation in IL-7-/- mice. J ournal of Immunology, 157: 2366-2377.

12. Crompton T, Outram SV, Buckland J \& Owen MJ (1998). Distinct roles of the interleukin-7 receptor $\alpha$ chain in fetal and adult thymocyte development revealed by an analysis of interleukin-7 receptor $\alpha$ deficient mice. European J ournal of Immunology, 28: 1859-1866.

13. Maraskovsky E, O'Reilly LA, Teepe M,
Corcoran LM, Peschon JJ \& Strasser A (1997). Bcl-2 can rescue T lymphocyte development in interleukin-7 receptor deficient mice but not in mutant rag- $\mathrm{I}^{-1}$ mice. Cell, 89: 1011-1019.

14. Moore N, Anderson G, Smith CA, Owen J J T \& J enkinson EJ (1993). Analyses of cytokine gene expression in subpopulations of isolate thymocytes and thymic stromal cells using semiquantitative polymerase chain reaction. European J ournal of Immunology, 23: 922-924.

15. Clarke D, Katoh O, Gibbs RV, Griffiths SD \& Gordon MY (1995). Interaction of IL-7 with glycosaminoglycans and its biological relevance. Cytokine, 7: 325-327.

16. Stephan RP, Reilly CR \& Witte PL (1998). Impaired ability of bone marrow stromal cells to support B-lymphopoiesis with age. Blood, 91: 75-88.

17. Kitazawa H, Muegge $K$, Badolata R, Wang JM, Fogler WE, Ferris DK, Lee CK, Candeias S, Smith MR, Oppenheim J J \& Durum SK (1997). IL-7 activates $\alpha 4 ß 1$ integrin in murine thymocytes. J ournal of Immunology, 159: 2259-2264.

18. Rodewald HR, Ogawai M, Hallen C, Waskow C \& Di Santo J P (1997). Prothymocyte expansion by c-kit and the common cytokine receptor $\gamma$ chain is essential for repertoire formation. Immunity, 6: 265-272. 